\title{
SERVICE-LEARNING PEDAGOGY IN A PROJECT MANAGEMENT COURSE: LEARNING BY DOING IN AN INFORMATION TECHNOLOGY CURRICULUM
}

\author{
Ruben A. Mendoza, Saint Joseph's University, rmendoza@sju.edu \\ Christina N. Outlay, University of Wisconsin - Whitewater, outlayc@uww.edu
}

\begin{abstract}
Courses utilizing service-learning (SL) pedagogy provide Information Technology/Information Systems (IT/IS) students the opportunity to put abstract concepts into real-world perspective while engaged in service to community organizations. In this paper, we describe efforts to transform and assess an Information Systems project management course using SL principles. We provide details regarding the redesign of course policies, development of assignment and grading rubrics, and use of in-class reflection activities. We also describe instructor experiences, course successes and challenges, and how student service activities can both facilitate and hinder the learning of project management materials. Finally, we share evaluation instruments and empirical data gathered to assess similarities and differences in student satisfaction between regular course offerings and the service-learning course. We hope our experience with this course will prove useful to faculty considering SL pedagogy in IT/IS curricula and will ultimately contribute to a larger body empirical evidence of service-learning student outcomes.
\end{abstract}

Keywords: Service-learning, IT Education, IS Education, Pedagogical Issues, Student Perceptions

\section{INTRODUCTION}

The use of service-learning (SL) pedagogy in Information Technology/Information Systems (IT/IS) courses is an increasingly popular choice in undergraduate curricula. The relative scarcity of research in this pedagogy area, however, means faculty seeking to develop a new course or transform an existing one often work without the benefit of resources to ease the task. In this paper, we provide analysis of our experience in transforming an existing IT/IS project management course to use SL pedagogy. We analyze and compare SL courses with non-SL courses and share evaluation instruments that may be useful to faculty looking to develop their own SL offering.

Service-learning pedagogy extends traditional classroom learning into the field by integrating meaningful community service with in-classroom activities [4, 21]. Students have the opportunity to convert theory and conceptual learning to applied, real-world knowledge [26] by working with community-based agencies to provide services related to the academic content of the course. Depending on the nature of the course, the service performed can be a direct application of content and skills learned in the classroom or, along with the community being served, the focus of classroom discussion using academic concepts covered in the SL course. Meaningful service activities meet real community needs and can be short-term engagements, i.e., volunteering at an event, or long-term opportunities such as weekly tutoring, the development of a business plan for the organization, etc.

SL courses offer students structured and unstructured reflection opportunities, whether individually or in groups, to assess the impact of their service on the communities they serve [4, 21]. SL has been called a 'balanced pedagogy' [6] in that it develops a sense of personal responsibility in students [1] while also benefitting both the communities being served and the students performing the service $[6,22]$. Service-learning activities outside the classroom can help students develop the personal and professional skills to help them better manage the uncertainty and complexity of managing daily business operations and of crafting business strategies [29, 7]. The benefits of SL courses for students include personal gains such as greater civic engagement, confidence, and student satisfaction, and increased academic performance as reflected by increased grade-point average, retention and degree completion rates, and the development of professional skills such as leadership, communications, critical thinking, and conflict resolution [27, $2,3]$. 
Service-learning courses are available in multiple academic disciplines, including health care [4], computer science [26], economics [7], management [29], ethics and leadership [12], accounting [26, 22], marketing [1], and information systems $[9,22,18,28,16]$. Until recently, use of SL pedagogy in the IT/IS fields was limited [28], resulting in scarce academic research on the topic $[11,14]$; this gap is receiving increasing attention by researchers. Hoxmeier \& Lenk [9] provide examples of SL projects over a decade in various courses such as Business Database Systems, Systems Development, Accounting Information Systems, and eBusiness. Rose et al. [22] describe student work in business process modeling and database design, and Preiser-Houy \& Navarrete [18] share their experience with a web development course. Other literature describes project management courses with differing analysis and requirements gathering stages but with similar database design and implementation experiences on behalf of community service-partners $[28,8,16,5,25]$. Very little of the existing literature, however, offers a quantitative analysis of the impact of SL courses on student learning or on student perception of SL pedagogy. As indicated from prior work on IT/IS experiences, faculty designing IT/IS-focused SL courses must account for several key considerations in addition to the initial resource development and coordination costs needed to deliver an SL course. IT/IS-focused SL courses are typically best suited for junior- and senior-level courses, when students are more likely to have a solid background in IT and the development process of an information system [13, 25]. Identifying clients with needs suitable to the course's learning objectives and students' limited IT/IS backgrounds and expertise often takes considerable time and effort. Additionally, coaching student teams and developing assignments to match community organization needs with learning objectives can take more effort than in a more traditional course format $[7,15]$.

Despite the increasing popularity of SL pedagogy, few resources exist to assist faculty in the design, development, and delivery of SL courses [22, 14], and empirical testing of SL learning outcomes [14] is largely missing from the literature. Hoxmeier and Lenk [9] provided an explanation and summary of SL examples and best practices and call for further research to empirically test the largely anecdotal results reported from prior research. Preiser-Houy \& Navarrete [18] provided a theoretical framework for IT/IS-focused SL courses using an exploratory case study method. Lee [14] offers qualitative research on an SL course offering. Wei et al [28] and Petkova [16] describe specific course implementations and materials, and next steps for performing qualitative analysis of their experiences in future work. To more rigorously assess the impacts of SL course delivery, Lee [14] described an SL course for systems design and conducted an analysis of student reflection essays to gather student feedback on the SL learning experience and perceived student outcomes. Like prior papers, Lee calls for additional research to quantitatively assess SL outcomes.

In this paper, we contribute to the growing body of SL literature by applying the service-learning pedagogy model proposed by Weis [29] to empirically examine course development and delivery. According to Weis [29], SL pedagogy consists of essential elements: a course planning stage, the service-learning experience, and reflection activities. The course planning stage is the time the instructor spends designing course objectives, identifying available pedagogical resources, matching community service partners to course objectives and backgrounds, and developing course materials and evaluation methods. The service-learning experience includes both the delivery of the academic content of the course by the instructor and the completion of service activities by students. Reflection activities are the collection of tasks an instructor designs and uses to help students and instructor alike digest and evaluate events taking place during service with the academic learning taking place in the classroom. Given that it is not unusual for service-learning courses to be limited in size (at least at this and similar Universities), our sample size is limited to the size of the class and student participation. However, our efforts can provide some design considerations, insights, and results that would ultimately contribute to a larger body of empirical evidence.

\section{SERVICE-LEARNING: COURSE CONTEXT \& CONTENT}

\section{Course Background}

The title of the course is Systems Analysis and Design (SAD) and is a requirement for juniors and seniors completing a business intelligence (BI) major in the business college of a mid-sized liberal arts university founded and run by the Jesuit order on the east coast of the United States. The course is also available as an elective to students completing a BI minor. The university has strong community-service programs and offers multiple SL options every semester, primarily in the English, Sociology, Philosophy, and Theology departments - courses in the 
social sciences and humanities that are considered a "more natural" home for SL courses [20]. At this University, while a few SL courses have been offered by faculty in the Accounting, Marketing, and Management departments, this is the first SL course offered in the BI major.

The BI major combines a basic background in IS in areas such as general IS, databases, and systems theory, with courses in statistics, data modeling, data mining, and other more specialized BI topics. The introductory information systems and database courses are the only courses students take which have IT/IS-specific content, since the emphasis of the major is on training business managers to appropriately handle and analyze data, and not on preparing students for technical support, software development, or data architecture roles. Students who enroll in the service-learning course have typically completed the introductory IS course and roughly half of them have also completed a database course.

At other universities, a course like this one can be taught with a focus on either IS project management or software engineering. At this university, the former approach is the most appropriate coverage area for this course for several reasons: project management is a core item in the essential body of knowledge of all business students [10] and is a highly-valued talent consistently listed at the top of employers' skills lists [17]. Locally, project management skills are also in great demand by employers of the University's BI graduates. Students do learn software engineering concepts as part of the course, but from a project-management perspective, as software development is also a core IT/IS project-management activity.

Students can elect to take either the SL version of the project management course or a more traditional (non-SL) version. In non-SL offerings of the course, students work in groups to prepare presentations on industry-based case studies highlighting IT/IS project failures. Class discussions, class participation, and illustration of course concepts are based on these materials. Industry representatives often visit the class as guest lecturers to share software project management stories, advice, and expertise. In the past few years, IT/IS professionals in the healthcare, consulting services, software development, retail, pharmaceutical, and insurance industries have shared their expertise with the class.

\section{Course Planning: Preparing for Service-Learning}

The instructor agreed to repurpose the course for the Fall 2012 semester at the request of the University servicelearning programs office and with departmental approval. Per University policy, however, the course is required for majors and students cannot be forced to take it as SL, therefore, a non-SL version also had to be scheduled the following semester for students not wishing to take an SL course. Beginning in the Spring 2012 semester, the instructor attended training provided by the university's SL program office, responsible for coordinating all servicelearning courses across the university. Through this training, the instructor learned background knowledge on service-learning objectives and developed ideas for the types of class and service-partner activities to build into the course. At this time, personnel from the SL program office began working with the instructor to identify and arrange meetings with potential service-partner organizations in the city where the campus is located. After several on-site visits to explain course objectives, general student capabilities, and define expectations, the instructor selected four non-profit organizations as service-partners for the course: a foundation supporting pediatric cancer patients and their families, a residential facility for the wheelchair-bound, and two community advocacy and services organizations.

Prior to the start of the semester, the instructor posted a one-page description of each service-partner organization and related course materials for students to review prior to the start of classes. At the instructor's direction, students formed groups during the first class session, and collectively ranked the four organizations in order of interest to their group. The instructor assigned service-partners to groups based on those rankings. The instructor intentionally did not assign roles to students in their groups to allow for students' natural leadership skills to fill those roles, with the full expectation that each group would experience some 'growing pains' and learning experiences as a result.

The instructor redesigned course assignments to include student presentations on the context and description of their projects, a mid-semester project progress update, and final report on the results of the project, in addition to two inclass exams and a final exam that covered the traditional academic content found in non-SL offerings of this course. 
Additionally, the instructor added optional readings to the schedule to provide students with background information on service-learning objectives. The instructor also rearranged the course format to allow graded structured and unstructured student reflection activities, to be completed both as individual homework and in class group activities.

The remaining group assignments were project-focused. Working in groups, students conducted their service, held conversations with their service-partners, and documented the context of their service and associated parameters for their deliverables. Later in the semester, student groups provided an update on their project progress. At the end of the semester, student groups produced a final project report, along with a reflection piece on the significance of their service and what they learned during the service experience.

Final grading items consisted of student peer evaluations and summary evaluations from service-partners. For the peer evaluation, students assigned a grade to each member of their group based on the member's contributions to the group's efforts. Service-partners also provided quantitative and qualitative feedback to the University servicelearning programs office; then the office provided summarized evaluation data for the course directly to the instructor. The instructor used both the peer and service-partner evaluations as a guide to assign individual service grades.

The actual content of the SL course teaching materials did not vary significantly from those used for non-SL offerings. Exams reflected in-class coverage and were also not significantly different from exams in non-SL offerings. However, due to the additional assignments and service project, the instructor's expectation at the start of the course was that students would spend somewhere between 2-4 additional hours per week (including service time) in the SL course than the students in the non-SL version of the course.

\section{The Service-Learning Experience}

In general, work performed by the students in the course was guided by service expectations defined prior to the start of the semester between the instructor and participating service-partner organizations. However, the reality of service completed by the students did not always match those expectations. For example, the work to be completed for the pediatric cancer foundation included the selection of tools to better manage the foundation's social media presence and outreach. To meet these objectives, students evaluated several tools, taking into consideration the lowlevel of staffing at the foundation, the lack of deep technical skills by the staff, and the lack of funds available to purchase any software application. The student group working with the foundation provided a recommendation for a fee-free open-sourced (public domain) application that was easy to use and provided the foundation with most of the capabilities they wished for, and a few they did not anticipate. The students also trained the staff on the use of the application software to not just manage but also automate their social media presence. The foundation's executive director was ecstatic with the results. However, due to the nature and somewhat unpredictable scheduling of the foundation's events, the students did not go to the foundation's office to do this work; they did it largely on their own from school. The students stayed in touch and visited the staff running the foundation and consulted appropriately every step of the way. Still, the type of service the students ended up providing was not the usual weekly on-site service at other agencies. Thus, students were unable to establish the type of service contact with the community served by the foundation the instructor had hoped for.

Similarly, the work students performed for the residential facility yielded mixed results. The students were asked to suggest improvements to a scheduling system the facility uses to have volunteers help residents with basic tasks (in some cases, it is as simple as "something rolled under the bed, can you help retrieve it?" The work the students initially did consisted only of a sign-up sheet. Following instructor intervention and recommendations for additional tasks, the students produced additional work, yet their contributions did not go beyond the recommendations provided by the instructor. While student on-site service met and exceeded expectations both for the service-partner and the student group, the work performed by the students was basic and only reflected instructor feedback, with no additional independent creativity or critical thinking displayed on the students' part. The students missed or ignored opportunities to apply course concepts, and the experience eventually morphed into a class with community service on the side, as opposed to the desired service-learning integrated experience. 
Students also experienced challenges working with the community advocacy and services organizations. For one organization, students helped the organization by collecting data from current and former clients on the impact of introducing fee-based services on service utilization and on the overall perception of the organization in the community. Based on the data they collected, students recommended exploring revenue options other than fees for these services, and helped to redesign a few processes for handling client interactions. However, the widespread lack of funds available to the organizations impacted the amount of work students could complete during the service experience. The staff with whom the students coordinated all activities changed a couple of times, and with those changes came schedule conflicts and changing service expectations. While the nature of the service did not change, students were frustrated by having to revisit service objectives with different staff members each time.

Despite some challenges, the second community advocacy and service organization provided the most stable and fruitful service and project management experience for students. The organization is part of a national network serving low-income communities by offering jobs, housing, and public-benefits counseling. Service contacts at the organization described the need for a method to collect client-experience data, i.e., success stories, for archival purposes to share with current and prospective clients. They also described the need to have students help staff explore a new case-management system rolled out by the national organization to identify capabilities and design reports and processes around those capabilities to better help them meet community needs. Students worked on the first objective but struggled with the online presence and storage limitations imposed by the central office. The student group nimbly adapted to these limitations and offered the organization a process design for the collection and archiving of client experiences that may be useful later on if this option becomes available.

\section{Service Learning Reflection}

Individual student reflection activities included two homework assignments. The first assignment was a weekly, hand-written reflection journal to be submitted to the instructor each week for signature. The second assignment was a personal letter each student submitted to the instructor in a self-addressed, sealed envelope for the instructor to return at the end of the semester. In addition to the sealed letter, students submitted another version of this letter (with an option to submit the same letter) to the instructor for review. The letter documented each student's individual expectations, apprehensions, and ideas about what the service component would entail, and served as a 'pre-treatment' record for students to reflect on at the end of the semester. The instructor used the review version of the letter to identify any issues students wished to share that may have had an effect on the service they were going to perform. If the instructor identified issues in the students' letters, the instructor held conversations with the students to assuage their concerns.

For in-class reflection, the instructor designated a period of time at the end of each class meeting. Individual participation in this reflection time was voluntary. During this time, students discussed course-related and personal experiences, sometimes with guidance from other undergraduate students who worked for the SL program office and help SL faculty lead classroom discussions of this nature.

\section{SERVICE-LEARNING RESULTS}

To assess SL impacts, we compared the individual course grading components across the SL and non-SL sections and noted some differences. Since 2003, the University had offered this course thirteen times as a non-SL course, and twice as SL. With the exception of minor updates to keep course materials relevant over time, the number and type of assignments remained consistent across all non-SL course offerings. Typically, non-SL courses featured three in-class assignments, each worth approximately $10 \%$ of the student's final grade. The assignments counted for a smaller percentage of the students' final grade for the course and so the instructor was more lenient in the grading for these assignments than the course exams.

For the first offering of the SL course, the instructor provided the same classroom coverage of topics and exams as non-SL courses. The instructor also graded assignments with similar leniency. Students received full credit for simply completing the individual assignments consisting of the reflection journal and personal letter (worth a combined $15 \%$ of the total grade). However, for the second SL course offering, the instructor provided greater parameters and reviewed submissions more closely. The instructor also graded group presentations (project 
description, status, and final report, also worth a combined total of $15 \%$ ) with much greater rigor, and used grading rubrics that measured the students' use of class concepts in the group presentations. Classroom content and exam coverage remained the same.

To assess the impact of the instructor's non-SL versus SL assignments and grading techniques, we used independent samples t-tests to compare several course-related factors. A comparison of the average grades for all assignments shows no statistical significance across all SL and non-SL offerings. However, comparing means of the group assignments shows a significantly lower average assignment grade for SL $(\mathrm{M}=83.77 \%)$ and non-SL $(\mathrm{M}=90.60 \%)$ courses $(\mathrm{p}<0.000)$. Average exam grades were also lower for the SL $(\mathrm{M}=79.15 \%)$ than non-SL $(\mathrm{M}=80.96 \%)$ course sections $(p<0.000)$; the differences in both assignment scores and exam scores also reflected in total course scores for SL ( $\mu=823$ points) vs. non-SL $(\mu=856$ pts) course sections $\mathrm{p}<0.05)$.

We also compared scores on university-provided SUMMA evaluation forms. SUMMA forms are standardized evaluation instruments to gather student course feedback. These forms include individual items in several categories and provide summary course results using principal component analysis. Among other feedback items, the SUMMA tool asks students to rate instructor presentations, course content and assignments, and demonstrated achievement of course objectives.

The means of selected items from the SUMMA evaluation form completed by students (Table 1) show no statistically significant difference between SL and non-SL courses in most measures of student satisfaction with the course. The only SUMMA factor to show a moderate difference is related to measuring course requirements and planning (Q3 and Q11). In this factor, the non-SL average score is higher than it is for SL offerings ( $\mu=4.59$ vs. 4.25, $\mathrm{p}<0.10$ ). This particular result is also observed (and magnified) when all SUMMA factor scores are combined into a single test, in which the average of all non-SL courses is statistically higher than it is for SL courses (4.50 vs. 4.30, $\mathrm{p}<0.05)$.

Table 1. Selected items from SUMMA evaluation forms (2006-2013). Item numbering reflects SUMMA form numbering. Item grouping was done by the author and does not reflect SUMMA form groupings.

\begin{tabular}{|l|c|c|c|}
\hline & $\begin{array}{c}\mu \\
\text { (SL, nSL) }\end{array}$ & F value & p value \\
\hline $\begin{array}{l}\text { Q2. The contents of the assignments contribute to my understanding of the } \\
\text { subject }\end{array}$ & $4.21,4.42$ & 0.814 & 0.279 \\
Q19. The out-of-class assignments are challenging & $4.47,4.60$ & 0.029 & 0.395 \\
\hline $\begin{array}{l}\text { Q21. The instructor relates underlying theory to practice } \\
\text { Q27. This course is practical and useful to those students for whom it was } \\
\text { specifically planned }\end{array}$ & $4.25,4.59$ & 0.800 & 0.093 \\
\hline $\begin{array}{l}\text { Q3. The requirements of the course (projects, papers, exams, etc.) were } \\
\text { explained adequately }\end{array}$ & & & \\
Q11. The course appears to have been carefully planned & & 0.538 \\
\hline $\begin{array}{l}\text { Q4. The instructor's presentation often causes me to think in depth about } \\
\text { this subject }\end{array}$ & $4.27,4.37$ \\
$\begin{array}{l}\text { Q14. Compared with other courses on this level carrying an equal amount } \\
\text { of credit, the effort I put into this course is as much as in other courses } \\
\text { Q18. In this course, I am learning much }\end{array}$ & 0.350 & \\
\hline $\begin{array}{l}\text { Q8. The instructor is teaching the course material or skills clearly } \\
\text { Q12. Course objectives are being achieved } \\
\text { Q15. Course objectives have been expressed clearly }\end{array}$ & $4.48,4.60$ & 0.196 & 0.415 \\
\hline All SUMMA items listed above & $4.30,4.50$ & 0.059 & 0.031 \\
\hline
\end{tabular}

In a second assessment, we developed a separate instrument and invited students in both course offerings to complete an anonymous online survey with questions related to various aspects of the course (Figure 1). Participation was completely voluntary and had no effect on course grade. The survey contained some items adapted from prior research and the rest were developed by the authors. Items adapted from Rose et al. [22] measured 
student satisfaction and effort, and the development of skills such as communication, leadership, client-interaction, and teamwork.

Of the thirty-six total students across both service-learning offerings (eighteen in each one), 11 completed the survey. The number is too low to permit robust statistical analysis, but large enough relative to total course registration to obtain some insights. Of the 11 students completing the survey, three were males and eight females, and there were seven juniors and four seniors. Six of the eleven students were Business Intelligence majors, two were BI minors, one was pursuing a degree outside the business school and completing the course as a free elective, and two did not report a curriculum or minor. Only one of the survey participants had completed a SL course prior to this one.

Figure 1 shows the means of survey items for the 11 participants. Student responses show moderate agreement with the appropriateness of this course as SL $(\mu=5.10)$, and with a statement suggesting the SL component helped them get a clearer understanding of project management $(\mu=4.90)$ and of course concepts $(\mu=4.67)$. This is consistent with empirical work supporting the notion that constructivist approaches, such as service-learning pedagogy, help students understand course objectives better [23]. Students also agreed the service-partner descriptions matched the work their groups completed $(\mu=4.80)$. Students indicated mild-to-moderate agreement that the overall experience contributed to students' development of various project management, leadership, communications, and teamwork skills. Based on the mean scores, students indicated disagreement with the length of the service period provided to complete the work they wished to complete $(\mu=3.30)$. The students also indicated the weekly reflection activities and assignments were not as useful as the instructor had hoped $(\mu=3.00)$. However, students also disagreed with the suggestion that the instructor assign roles, indicating that not assigning specific roles to group members was the better option $(\mu=2.83)$. This last result differs from research suggesting the instructor assign roles to students in each team [26].

\begin{tabular}{|l|l|l|}
\hline Please indicate your level of agreement with the following statements \\
\hline (7-point Likert scale. $1=$ Strongly disagree, $7=$ Strongly agree) \\
\hline There should be more Service Learning courses in the Business School \\
\hline There should be more Service Learning courses in the Business Intelligence major/minor \\
\hline This course was an appropriate course to offer as a service learning course \\
\hline The service component hel ped you get a clearer understanding of general project management concepts & $\mathbf{n}$ \\
\hline The service component hel ped you get a clearer understanding of course concepts \\
\hline The project description as provided by the service partner matched the work your group was expected to complete \\
\hline The length of the service period was sufficient to complete the goals your team set out to complete \\
\hline It would have been helpful if the instructor had assigned roles (project manager, technical specialist, change manager, etc.) to each student in each group & 4.73 & 11 \\
\hline In-class reflection activities were useful & 4.00 & 11 \\
\hline Weekly journal assignment was us eful & 5.10 & 10 \\
\hline Your awareness of the issues surrounding the community served by your partner organization has increased as a result of this course \\
\hline Your journaling activities helped you reach deeper awareness of the issues surrounding the community served by your partner organization \\
\hline As a result of this course you feel better prepared as a future project manager \\
\hline As a result of this course you have greater confidence in your skills as a project manager \\
\hline As a result of this course you have a better understanding of project management issues you are likely to face as a business professional \\
\hline As a result of this course you learned a great deal about interacting with business clients \\
\hline
\end{tabular}

Figure 1. Online Survey Results

\section{CONCLUSIONS}

In this paper, we recounted one instructor's experiences by using Weis' [29] three-stage SL model to modify a course on IS project management to include the SL pedagogy. To contribute to the literature, we also performed quantitative analysis of the impact of SL delivery on student perceptions and performance and compared SL versus non-SL approaches to teaching the same course. Mirroring the larger structure of this article, this conclusions section will offer lessons learned for all activities using the same three stages described by Weis [29]: planning, service-learning experience, and reflection.

\section{Planning}

The selection of appropriate service-partners was critical to the success of the course. Meeting with potential partners to provide them an accurate description of course coverage and student capabilities helped to ensure the proper context was created for expectations on the part of students and service-partners alike. The biggest issue 
confronted by the instructor, however, was the realization that the part of service related directly to course content has to be defined more narrowly for the students. Typical of IS courses [24], students enrolling in this course do not have a deep level of technical expertise. The lack of substantial technical expertise and 'fluency' with the language of IT/IS limits the range of deliverables one can expect from students. Delivering appropriate IT/IS courses to undergraduate students requires a delicate balance so materials covered are not too simplistic (office productivity tools such as the Microsoft suite), not too complex (systems development and implementation are heavily contextual and difficult to teach in a single semester), and relevant beyond simple memorization of facts to students with little business or systems expertise [19]. The difficulty is compounded when some of the learning takes place outside the classroom, away from the instructor's direct control.

Lazar and Lidtke [13] observe that an IT/IS course using the SL pedagogy is suitable for juniors and seniors who "have a thorough understanding of the issues involved in the process of developing an information system," which is the primary objective of the course. This places greater importance on the selection of appropriate servicepartners, and on the proper framing of project activities and deliverables for student groups. Another option is to offer this course as a non-SL course every fall and offer an SL variant of the course in the spring as an elective. This would make DB and the non-SL project management course a pre-requisite for the spring elective, an approach successful at other institutions [16]. Unfortunately, this would result in increased demand on teaching loads and knowledge requirements for existing faculty.

\section{Service-Learning Experience}

As suggested in previous research, flexibility and faith in the ability of students [29] helped create successes in the course. Willingness by the instructor to adjust to changes in staff, resources, expectations, and objectives was key to providing students reassurance that their grade was not strictly tied to the project expectations document at the start of the course. In fact, documenting expectations clearly and communicating changes on a timely basis reinforced to students the project management skills covered in the classroom better than anticipated. Placing faith in students' ability to recognize and adjust to changes facilitated the experience much more than rigid expectations and grading criteria would have.

Overall, the service experience from the point of view of the students ranged from a missed opportunity to obvious and immediate applicability of classroom concepts. A consistent theme expressed by the students, and which took several weeks for them to be able to articulate, was that the nature of the project management activities performed imposed a distance on the service they expected to complete for the organization. The work the students did was not the typical SL work (at least at this university) in which students tutor someone or help them create a resume or fill out city/state/fed benefits forms. They were doing work for the organization instead, to help multiply/amplify the impact of the organization's work.

Since the students were not directly working with the clients of the service organizations, they had difficulty "seeing" the impact of their work. This experience is echoed in existing literature in various ways. Resnick [20] describes the difficulties in finding the "sweet spot" between the needs of a service organization and the development and refinement of student skills sought by faculty. Outlay \& Ciganek [15] describe the tension between finding that sweet spot and students' wishes to have more control over service-partner selection and staffing, and over the duration of the service experience. After several conversations during the structured reflection part of each class session, it became apparent students felt service for the organization was not the same as service to the organization's clients, and that this distance diminished the perception of the impact they were really having on the service-partner. The instructor learned from this student feedback, which will be very useful in providing context to the next cohort of SL students in the course.

Student feedback also revealed time spent in service was insufficient for the student groups' project service goals. An additional 2-3 weeks of service would help students obtain first-hand experience with the service-partner's services and clientele, and alleviate the separation of service issues just described. The instructor will also incorporate this realization into a future SL course. 


\section{Reflection Activities}

Of all course-related activities, reflection activities were perhaps the greatest challenge for the instructor. Govekar and Rishi [7] urge patience on the part of the instructor, saying faculty "need practice to get it right." The instructor, with prior deeply technical professional and academic training and experience, felt quite unprepared to adequately lead reflection exercises. The result was a set of structured reflection assignments (journals and letters) that eliminated the need to evaluate personal student writing. Zlotkowski [30] calls this a "fear of introducing topics in which the instructor has no educational background or... expertise" and was a barrier to full effectiveness of the course. Clearly, the instructor needed to learn more regarding the clarity of expectations around rigorous reflection which Weis [29] identifies as critical to success. The University personnel provided the instructor with examples of more successful reflection questions that were used with moderate success (due to the lateness of the change and the fact that a change in grading expectations was not possible), but that will inform and guide the next SL offering of the course.

Looking at student feedback and performance, we found no significant differences in student individual assignment performance across all SL and non-SL offerings. However, we did find a difference in group assignments across SL and non-SL courses, with SL group assignments receiving lower scores than non-SL. This could be due to the greater grading rigor with which the instructor scored SL group assignments. Curiously, though, average exam grades were also lower for the SL sections. The lower score for the average exam grade is unexpected because classroom coverage of topics and exams was not at all different between SL and non-SL courses over this period of time. This finding is consistent with existing research, though, which shows mixed results in performance and skills, and could simply be a random effect. Rose et al. (2005) reported that performance differences showed up only in essays, not in the multiple-choice portion of graded assignments and describe improvements in life skills but not in academic or career skills.

Items from the SUMMA evaluation form completed by students show no statistically significant difference between SL and non-SL courses in most measures of student satisfaction with the course, including items measuring ideas such as the quality and rigor of course assignments, clarity of learning objectives and success in achieving the same, quality of student/instructor interaction, and the applicability of concepts to practice. The only SUMMA factor to show a moderate difference is one measuring course requirements and planning. In this factor, the non-SL average score is higher than it is for SL offerings $(\mu=4.59$ vs. $4.25, \mathrm{p}<0.10)$. This particular result is also observed (and magnified) when all SUMMA factor scores are combined into a single test, in which the average of all non-SL courses is statistically higher than it is for SL courses $(4.50$ vs. $4.30, p<0.05)$. Generally speaking, this is not a surprising result given any instructor's inability to control the details of the service experience itself and, in particular, service with non-profit organizations which are typically strapped for resources. This lack of resources often causes unanticipated service and resource disruptions that directly affect the student experience. Combined with the results for all assignments described earlier, it suggests there is, in fact, a premium to be paid in SL courses on student evaluations as a result of the unpredictable nature of "real-world" service work and the lack of control an instructor must give up when dealing with outside partners and scenarios rather than pre-planned, specifically designed and predictable assignments such as problem-solving activities and case studies.

\section{LIMITATIONS}

Service-learning gives students an opportunity to apply classroom concepts to real-world situations while benefitting community organizations. Research on the use of SL pedagogy in the IT/IS fields is limited, and what little exists shows the applicability of SL to IT/IS courses. For courses such as the one described in this article, prior student exposure to technology/systems concepts, database design, and project management would greatly enhance the delivery of the service to the community. The challenge of guiding meaningful reflection activities is typically outside the training and expertise of IT/IS instructors, but some practice and a willingness to "let go" of some control over the learning objectives of IT/IS courses can help enhance the course experience for our students.

This paper has several limitations and observations that provide opportunity for additional research to build on our findings. Results of this paper are limited due to the small sample size in both SL courses offered and student enrollment, which is kept low at this university due to the additional workload of service-learning courses. In addition, the small number of feedback forms returned by students does not permit the kind of rigorous statistical 
analysis that would allow us to make stronger and more generalizable conclusions. Empirically evaluating additional SL course offerings at this and other Universities can permit further development and refinement of measurement tools, and the use of more sophisticated data analysis techniques.

Some useful observations include the enthusiastic response of students to their exposure to "real-world" project management situations, and the impact of even limited service by these students on the partner organizations' abilities to offer more and better services to the communities they serve. It is also worth noting this paper provides evidence of a course-evaluation premium paid by faculty members due to the unpredictability of service work outside the classroom. This premium has been described and suggested in previous literature, but (to our knowledge) no empirical evidence of this premium has yet been provided. Though modest, the evidence presented in this work reveals there is truth to the idea and is worth further investigation.

\section{REFERENCES}

1. Andrews, C. P. (2007). Service learning: Applications and research in business. Journal of Education for Business, 83(1), 19-26.

2. Astin, A. W., \& Sax, L. J. (1998). How undergraduates are affected by service participation. Journal of College Student Development, 39(3), 251-63.

3. Berson, J. S., \& W. F. Younkin. (1998). Doing well by doing good: A study of the effects of a service-learning experience on student success. In American Society of Higher Education. Miami, FL.

4. Cauley, K., Canfield, A., Clasen, C., Dobbins, J., Hemphill, S., Jaballas, E., \& Walbroehl, G. (2001). Service learning: Integrating student learning and community service. Education for Health, 14(2), 173-81.

5. Chuang, K. W. C., \& Chen, K. C. (2013). Designing service learning project in systems analysis and design course. Academy of Educational Leadership Journal. 17(2), 47-60.

6. Furco, A. Service-learning: A balanced approach to experiential education. Expanding Boundaries: Serving and Learning, 1, 1-6.

7. Govekar, M. A., \& Meenakshi R. (2007). Service learning: Bringing real-world education into the B-school classroom. Journal of Education for Business, 83(1), 3-10.

8. Grant, D. M., Malloy, A. D., Murphy, M. C., Foreman, J., Robinson, R. A. (2010). Real world project: Integrating the classroom, external business partnerships and professional organizations. Journal of Information Technology Education: Innovations in Practice, 9, 167-196.

9. Hoxmeier, J. \& Lenk, M. M. (2003). Service-learning in Information Systems courses: Community Projects That Make a Difference. Journal of Information Systems Education, 14(1), 91-100.

10. Ives, B., Valacich, J., Watson, R. T., Zmud, R., Alavi, M., Baskerville, R., . \& \& Whinston, A. B. (2002). What every business student needs to know about information systems. Communications of the Association for Information Systems, 45(9), 467-77.

11. Johnson, R., \& Ping, J. (2005). Service learning it is: Teaming with community and industry. Paper presented at the Pacific Asia Conference on Information Systems, Bangkok, Thailand.

12. Kolenko, T. A., Porter, G., Wheatley, W., \& Colby, M. (1996). A critique of service learning projects in management education: Pedagogical foundations, barriers, and guidelines. Journal of Business Ethics, 15, 13342.

13. Lazar, J., \& Lidtke, D. (2002). Service-learning partnerships in the Information Systems curriculum. In Managing It/Community Partnerships in the 21 st Century, edited by Jonathan Lazar. Hershey, PA: Idea Group.

14. Lee, R. L. (2012). Experience is a good teacher: Integrating service and learning in Information Systems education. Journal of Information Systems Education. 23(2): 165-176.

15. Outlay, C. N., \& Ciganek, A. P. (2012). LEAPing forward: A case study employing high impact practices in undergraduate education. Southern Association for Information Systems, Atlanta, GA.

16. Petkova, O. (2012). Reflections on service-learning projects in Information Systems project management and implementation course. In Information Systems Educators Conference. New Orleans, LA.

17. Pratt, M. K. (2012). 10 hot it skills for 2013. ComputerWorld, Retrieved May 152012.

18. Preiser-Houy, L., \& Navarrete, C. (2006). Exploring the learning in service-learning: A case of a communitybased research project in a web-based systems development. Journal of Information Systems Education, 17(3), 273-84. 
19. Recker, J., \& Alter, S. (2012). Using the work system method with freshman information systems students. Journal of Information Technology Education: Innovations in Practice. 11-24.

20. Resnick, P. (2013). Service-learning in the Computer and Information Sciences: Practical applications in engineering education. Michigan Journal of Community Service Learning, 95-99.

21. Rhoads, R. A. (1998). Academic service-learning: A counternormative pedagogy. In Academic Service Learning: A Pedagogy of Action and Reflection, edited by Robert A. Rhoads and Jeffrey P. F. Howard. San Francisco: Jossey-Bass.

22. Rose, J. M., Rose, A. M., \& Nordman, C. S. (2005). A service-learning course in Accounting Information Systems. Journal of Information Systems, 19(2), 145-72.

23. Sardone, N. B. (2011). Developing information technology fluency in college students: An investigation of learning environments and learner characteristics. Journal of Information Technology Education. 10, $101-122$.

24. Scott, E. (2008). From requirements to code: Issues and learning in IS students' systems development projects. Journal of Information Technology Education: Innovations in Practice, 7.

25. Smith, K. D., Estep, M., Zhao, C., Moinian, F., \& Johari, A. (2014). Combined discipline xapstone teams: Using service learning to provide a business solution. Issues in Information Systems, 15(2): 8-13.

26. Tan, J., \& Phillips, J. (2005). Incorporating service learning into Computer Science courses. Journal of the Consortium for Computing Sciences in Colleges, 20(4), 57-62.

27. Toncar, M. F., Reid, J. S., Burns, D. J., Anderson, C. E., \& Nguyen, H. P. (2006). Uniform assessment of the benefits of service learning: The development, evaluation, and implementation of the Seleb Scale. Journal of Marketing Theory and Practice, 14(3), 223-38.

28. Wei, K., Siow, J., \& Burley, D. (2007). Implementing service-learning to the Information Systems and Technology Management program: A study of an undergraduate capstone course. Journal of Information Systems Education, 18(1), 125-36.

29. Weis, W. L. (2000). Service-learning in Business curricula: Walking the talk. National Society for Experiential Education Quarterly, 11-16.

30. Zlotkowski, E. (1996). Opportunity for all: Linking service-learning and Business education. Journal of Business Ethics, 1. 